FITRAH Jurnal Kajian Ilmu-ilmu Keislaman

Vol. 05 No. 1 Juni 2019

e-ISSN : 2460-2345, p-ISSN: 2442-6997

Web: jurnal.iain-padangsidimpuan.ac.id/index.php/F

\title{
HADIS TENTANG DILAKNAT PEREMPUAN YANG MENOLAK PANGGILAN SUAMINYA
}

\author{
MUHAMMAD AMIN \\ IAIN Padangsidimpuan \\ Email : muhammad.amin7010@gmail.com \\ DOI: $h$ ttp://dx.doi.org/10.24952/fitrah.v5i1.1810
}

\begin{abstract}
Abstrak
Hadith about the cursing of the woman who refused the call of her husband, seen from her sanad was considered valid by Imam Bukhari and Muslim, and Imam Tirmizi judged it by hasan sahih gharib. The meaning of the husband taking his wife to bed (firasy) is a figurative meaning. The real meaning is to invite to do jima. The meaning of the wife rejecting the husband's invitation is not fulfilled by the invitation of the husband to do jima 'without any age syar'i, such as fasting fardu and ihram. The intention of the husband is angry with his wife for not carrying out his obligations and giving him the rights of her husband One of the rights of the husband is in the wife's body that is channeling lust and having fun, If the rights of this husband are not fulfilled by the wife, then it brings God's anger, unless He bestows His forgiveness.
\end{abstract}

Keywords: Woman, Jima', Husband

\begin{abstract}
Abstrak
Hadis tentang dilaknatnya perempuan yang menolak panggilan suaminya, dilihat dari sanadnya dinilai sahih oleh Imam Bukhari dan Muslim, dan Imam Tirmizi menilainya dengan hasan sahih gharib. Makna suami mengajak istri ke tempat tidur (firasy) merupakan makna kiasan.Makna yang sesungguhnya adalah mengajak untuk melakukan jima'. Adapun makna Istri menolak ajakan suami adalah tidak dipenuhi ajakan suami untuk melakukan jima' tanpa ada uzur syar'i, seperti puasa fardu dan ihram. Adapun maksud suami marah kepada istri karena tidak melaksanakan kewajiban dan memberikan hak suaminya. Salah satu hak suami ada pada badan istri yaitu menyalurkan syahwat dan bersenang-senang, Jika hak-hak suami ini tidak dipenuhi oleh istri, maka mendatangkan kemarahan Allah, kecuali Dia melimpahkan ampunan-Nya.
\end{abstract}

Kata Kunci: Perempuan, Jima', Suami

\section{PENDAHULUAN}

Hadis sebagai panduan hidup umat Islam, baik dalam hal hubungan dengan Allah maupun hubungan sesama manusia.Diantara hubungan sesama 
FITRAH Jurnal Kajian Ilmu-ilmu Keislaman

Vol. 05 No. 1 Juni 2019

manusia adalah tentang pernikahan membina rumah tangga yang merupakan sunnatullah dalam kehidupan manusia yang lazim disebut dengan istilah perkawinan.Diantara tujuan perkawinan adalah melanjutkan keturunan, mendapatkan ketenangan (sakinah), menyalurkan nafsu syahwat yang syah, dan lain-lainnya.Tujuan ini tentunya teraflikasi dalam kehidupan berumah tangga pasangan suami istri. Rumah tangga yang di bina tentunya tidak selamanya mengalami kelanggenganan dan keindahan, tetapi kadangkala akan mengalami permasalahan berupa ganjalan dan goncangan dalam membinanya. Permasalahan ini bisa saja di latarbelakangi faktor ekonomi, budaya, adat, karakter pasangan dan lain sebagainya, sehingga memunculkan rasa tidak enak pada suami atau istri.

Rasa tidak enak (rasa tak senang) ini dapat mengakibatkan keributan atau percekcokan dalam rumah tangga, lambat laun menjalar sampai ke masalah tempat tidur (firasy).Tempat tidur seharusnya merupakan tempat yang indah, bahagia, nyaman, menjadi tempat yang tidak mengenakan dan memunculkan murka (marah atau ghalab) di dalam diri suami.Salah satu faktornya karena istri tidak mau mendampingi suami tidur bersama di tempat pembaringan (jima').

Permasalahan yang spesifik ini tidak luput dari sorotan hadis Nabi, yang mana dikatakan jika suami mengajak istrinya untuk menuju tempat tidur (firasy), lalu istri tidak memenuhi, maka malaikat melaknat istri tersebut sampai subuh.

Tulisan yang singkat ini berupaya membahas permasalahan tersebut dengan harapan ditemukan kajian yang kompleks tentang makna-makna, hukum-hukum bagi istri yang tidak mau memenuhi ajakan suami berjima'. Maka dalam tulisan ini akan di bahas tentang kualitas hadis, pengertian mengajak ke tempat tidur, menolak atau enggan untuk memenuhi ajakan suami, Suami dalam keadaan marah, Malaikat melaknat sampai subuh.

\section{KAJIAN TEORI}

1. Apabila suami memanggil (istri) ke tempat tidur

Kata $d a^{\prime} a$ pada pada hadis ini bermakna panggilan, seruan, dan ajakan serta segala kata yang semakna dengannya. ${ }^{1}$ Dalam hadis ini maksudnya adalah suami mengajak istri untuk melakukan hubungan (seks). Hubungan seks

\footnotetext{
${ }^{1}$ Warson Munawir. Kamus al-Munawir, (Jakarta: Pustaka progresif, 1997), hlm.404. Samsur Munir. Ilmu Dakwah, (Jakarta: Amzah, 2009), Hlm. 3.
} 
merupakan gabungan dan prilaku seseorang yang tidak hanya didasarkan pada ciri seks secara biologis tetapi juga merupakan suatu aspek kehidupan manusia yang tidak dapat dipisahkan dari aspek kehidupan lain. Sarwono menjabarkan aktivitas seksual mulai dari berpegangan tangan, berpelukan, bercumbu, meraba bagian tubuh yang sensitif, sampai pada senggama. Dalam agama islam hubungan seksual sebagai sunnah rasul setelah menikah. ${ }^{2}$ Suami istri yang saling berpandangan, saling bercanda dan merayu saja akan bernilai pahala apalagi bila lebih daripada itu karena tujuan utama berhubungan seksual dalam islam adalah untuk memperoleh keturunan, dan itu sangat dianjurkan oleh Rasulullah. ${ }^{3}$

Hubungan seksual bukan hanya sekedar hubungan fisik, ini adalah simbol dari satu relasi spritual dan ekspresi dari kesatuan yang komplit dari dua orang yang menikah. Jadi hubungan fisik tersebut menjadi satu konfirmasi dari kesatuan menyeluruh. ${ }^{4}$

\section{Dilaknat Malaikat}

Kata laknat berasal dari bahasa arab yang bermakna menjauhkan dan menyingkirkan kebaikan. Dikatakan demikian jika berasal dari Allah. Jika berasa dari makhluk maknanya adalah cacian dan doa. Laknat adalah kata benda (ism) bentuk jamaknya li'aan dan la'anaat. ${ }^{5}$ Adapun secara istilah bermakna menjauhkan dari rahmat Allah dan pahalanya. ${ }^{6}$ Oleh karena itu segala hal yang dilaknat oleh Allah dan rasul-Nya berdasarkan dalil, maka termasuk dosa besar. Menurut Usaimin semua perbuatan yang dilaknat rasul-Nya masuk dalam kategori dosa besar. ${ }^{7}$

Adapun hal-hal yang termasuk dilaknat oleh Allah dan Rasul-Nya berdasarkan dalil-dalil berikut ini: 1). Iblis, berdasarkan surat al-Hijir ayat 33-35. 2). Orang Kafir, berdasar surat al-Baqarah ayat 161-162, 3). Orang-orang kafir dari Bani Isra'il (yahudi), berdasarkan surat al-Maidah ayat 78-79, 4). Orang

2Salim A. Fillah. Nikmatnya Pacaran Setelah Menikah, (Yogyakarta: Pro-U Media, 2008), Hlm.35.

${ }^{3}$ Muhammad Fauzil adhim, dkk. Menikah Memuliakan Sunnah, (Yogyakarta: Darul Haq, 2013), Hlm. 35.

4Julianto Simanjuntak, https://www.kompasiana.com, 15 Nopember 2011 / diperbarui 15 Nopember 2011, diakses tanggal 5 April 2019.

5Ibn Manzur. Lisan al-Arab, (Madinah: Dar al-Hadis, 2002), Hlm. 4044.

${ }^{6}$ Mahmud bin Ahmad Badr al-Din al-Aini. Umdatul Qari, (T.tp: Idarat ath-Thiba'ah alMuniriyah, 2012) juz. XII, Hlm. 117.

${ }^{7}$ Muhammad bin Saleh al-Usaimin. Durul wa fatawa al-Haram al-Madani, (Beirut: Dar alFikr, 2007), Hlm. 57 
FITRAH Jurnal Kajian Ilmu-ilmu Keislaman

Vol. 05 No. 1 Juni 2019

Zalim yang berdusta atas nama Allah, berdasarkan surat al-Huud ayat 18, 5). Orang yang menyakiti Allah dan Rasulnya, surat al-Ahzab 57, 6). Orang yang berbuat kerusakan di muka Bumi dan memutuskan silaturrahim berdasarkan suart muhammad ayat 22-23, 7). Orang yang menyembunyikan ilmu berdasar surat al-baqarah 159-160, 8). Suami atau istri yang berdusta saat li'an berdasarkan surat an-Nuur ayat 6-9,10). Orang yang melakukan nikah tahlil berdasarkan riwayat at-Tirmizi no 1120.11). Istri yang menolak ajakan suaminya tanpa alasan yang dibenarkan syariat, ini berdasarkan riwayat al-Bukhari no. 5193 dan yang lain sebagaimana yang terdapat dalam tulisan ini. 11). Masih banyak lagi hal-hal lain yang dilaknat oleh Allah dan rasul.

\section{METODE}

Kajian ini merupakan kajian perpustakaan (Library reseach), yang mana data-datanya diperoleh dari perpustakaan berupa buku-buku, majalah, dokumen, dan yang lainnya. Adapun jenis penelitian merupakan penelitian hadis, maka pendekatan yang digunakan ilmu takhrij al-hadis, dengan langkahlangkah di mulai dari menemukan hadis di kitab mana saja ditemukan (khusus kitab sembilan), dalam rangka menemukan siapa saja mukharrij yang meriwayatkan hadisnya sekaligus memaparkan hadis-hadis yang ditemukan. ${ }^{8}$ Setelah itu dipaparkan penilai-penilaian ulama tentang kualitas hadis, lalu dipaparkan dengan ayat-ayat yang berkaitan. Karena kajian ini fokus pada kajian matan hadis, maka metode yang digunakan metode tahlili, yaitu menafsirkan hadis dengan memaparkan segala aspek yang terkandung di dalam matan tersebut serta menerangkan makna-makna yang tercakup di dalamnya sesuai dengan keahlian dan kecendrungan pensyarah hadis terhadap matan tersebut. ${ }^{9}$

\section{PEMBAHASAN}

\section{Mukharrij Hadis}

Hadis tentang Dilaknatnya perempuan yang menolak panggilan suaminya, ditelusuri dalam kitab Mu'jam Hadis karya A.J. Wensick, melalui kata da'a dan batat ditemukan bahwa hadis tersebut diriwayatkan oleh Imam al-Bukhari dalam

${ }^{8}$ Mahmud at-Tahhan. Usul al-Takhrij wa Darah al-Asanid, (Beirut: Dar al-Quran al-Karim, 1979), Hlm. 27

${ }^{9}$ Lihat Nasiruddin Baidan. Metodologi Penafsiran Al-quran, ((Yogyakarta: Pustaka Pelajar, 1997), Hlm. 31 
kitab Bida' al-khalqi bab 7, dan kitab nikah bab 85. Diriwayatkan Im $\pm m$ Muslim dalam kitab nikah nomor hadis 121 dan kitab Talaq nomor hadis 10. Diriwayatkan Imam Abi Dawud dalam kitab nikah bab 40. Diriwayatkan Imam ad-Darimi dalam kitab nikah bab 23. Kemudian diriwayatkan Imam Ahmad bin Hanbal Juz. 2 halaman 255, 348, 386, 439, 468, 480, dan 519.10

Dari periwayatan lima mukharrij di atas ditemukan 14 hadis yang membicarakan tentang masalah ini. Dari 14 hadis di atas ditingkat sahabat hanya ada satu periwayat yaituAb-Hurairah. Sedangkan ditingkat Tabi'in ada dua periwayat yaitu: Abi 'Azzim dan Zur'rah bin 'Aufa al-Amir's. Dalam hal ini tidak ada syahid pada tingkat sahabat, karena sahabat yang menerima hadis ini hanya Abi Hurairah. Adapun di tingkat tabi'in ada tabi' karena diriwayatkan oleh dua orang periwayat yaitu: Abi 'Azim al-Asja'i dan Zur'rah bin 'Aufa al-Amiri.

Untuk menghemat lembaran makalah ini, disini penulis tidak memaparkan hadis-hadis yang sanad dan matannya memiliki redaksi yang sama kecuali berbeda periwayat di tingkat sahabat, sebagai berikut :

a. Riwayat Imam Bukhari pada kitab Bida' al-khalqibab 7 :

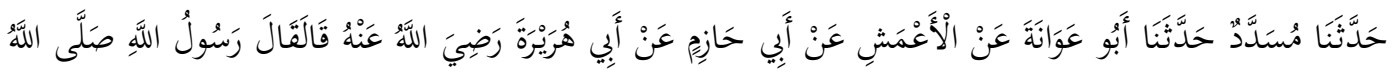

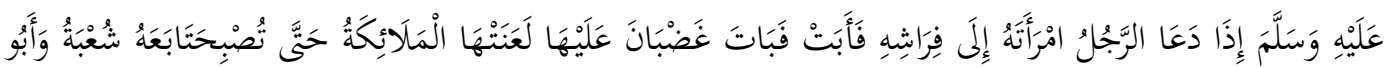

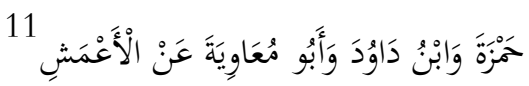

b. Riwayat Imam al-Bukhari pada kitab kitab nikah bab 85

Hadis Pertama:

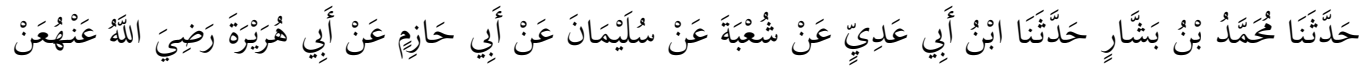

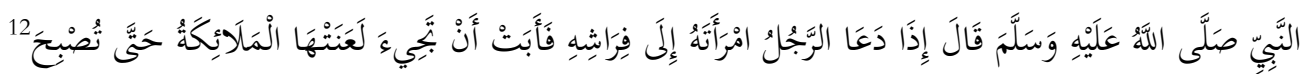

Hadis yang kedua

${ }^{10}$ Wensick, A.J. Al-Mu'jamal-Mufahras li ahadisin an-Nabawi, (Leiden: E.J. Brill, 1942, juz.VI. Hlm. 124 dan 194.

${ }^{11} \mathrm{Abu}$ Abdillah Muhammad bin Ismail al-Bukhari. Sahih al-Bukhari, (Beirut: Dar al-Mutabi' Sya'bi, T.th), Juz. III, Hlm. 135.

${ }^{12}$ Ibid., Juz.II. Hlm. 147. 
FITRAH Jurnal Kajian Ilmu-ilmu Keislaman

Vol. 05 No. 1 Juni 2019

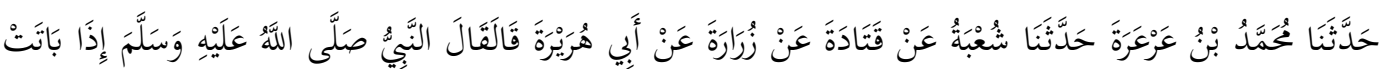

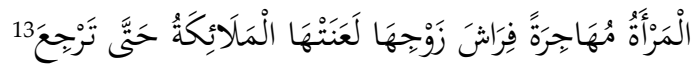

c. Riwayat Imam Muslim pada Kitab Nikah nomor hadis 121 :

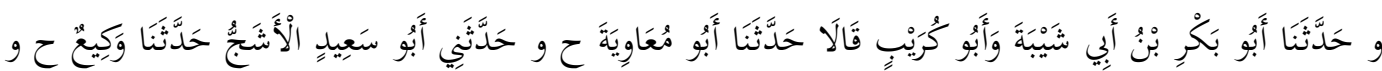

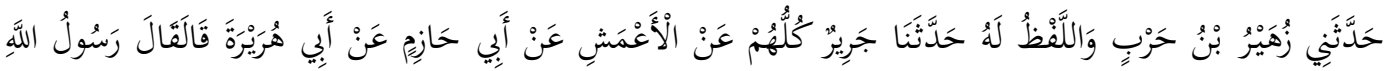

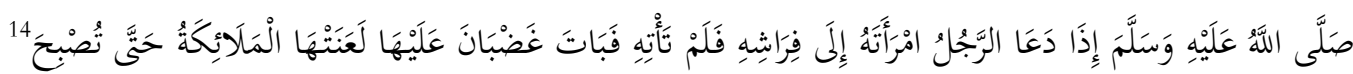

d. Riwayat Imam Muslim kitab Talaq nomor hadis 10:

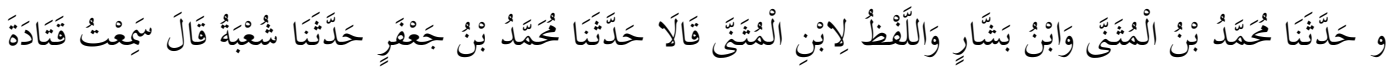

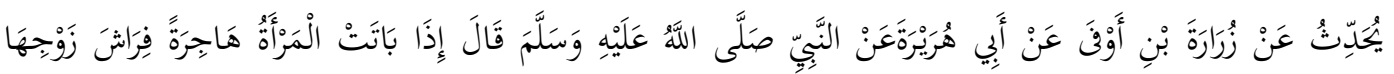

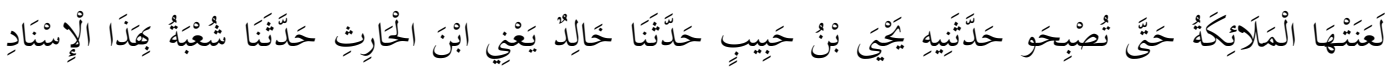

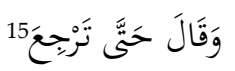

e. Riwayat Imam Abi Dawud pada kitab nikah bab 40 :

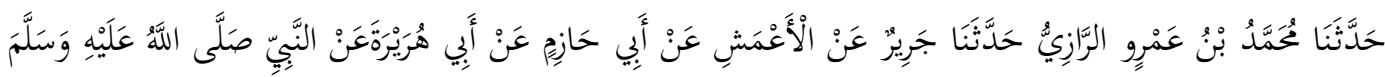

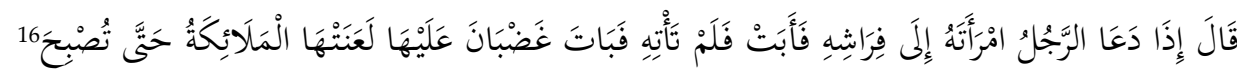

f. Riwayat Imam ad-Darimi pada Kitab Nikah bab 23.

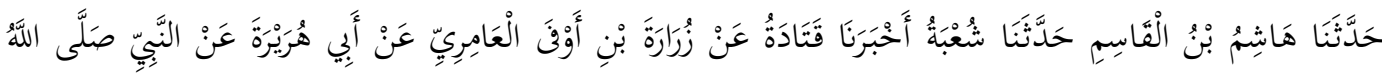

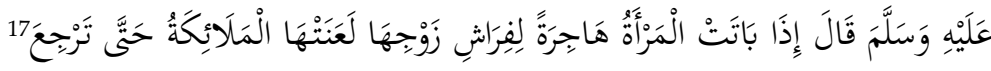

g. Riwayat Imam Ahmad bin Hanbal Juz. 2 halaman 255, 348, 386, 439, 468, 480, 519, dan 538

Hadis halaman 255

${ }^{13}$ Ibid., Hlm. 148.

${ }^{14} \mathrm{Abu}$ Husin Muslim bin Hajjaj al-Qusayri an-Naisaburi, Sahih Muslim, (Kairo: Maktabah al-Misriyah, T.th), Juz. II, Hlm. 178.

${ }^{15} \mathrm{Abu}$ Husin Muslim bin Hajjaj al-Qusayri an-Naisaburi, Sahih Muslim, (Kairo: Maktabah al-Misriyah, T.th), Juz. II, Hlm. 213.

16 Abu Dawud Sulaiman al-Asy'ab as-Sijistani., Sunan Abu Dawud, (Beirut: Dar al-Fikr. T.th), Juz. III, Hlm. 254.

17Imam ad-Darimi, Sunan ad-Darimi, (Libanon; Dar al-Fikr, 1998), juz. II, Hlm. 40. 


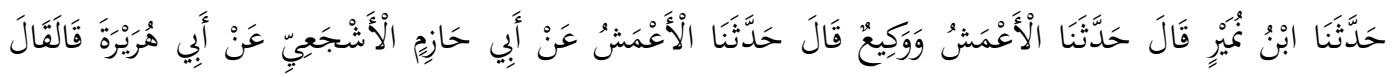

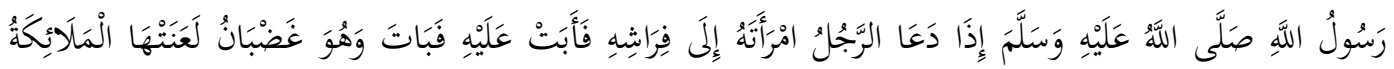

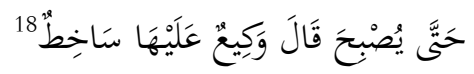

\section{Hadis Halaman 348}

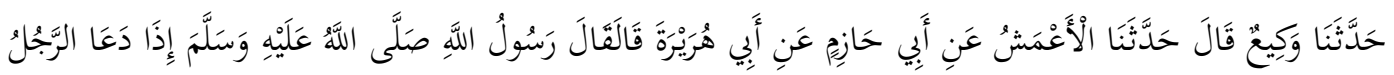

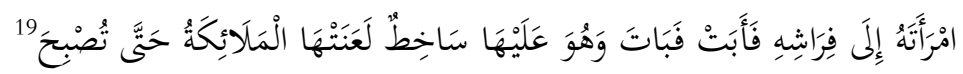

\section{Hadis Halaman 386}

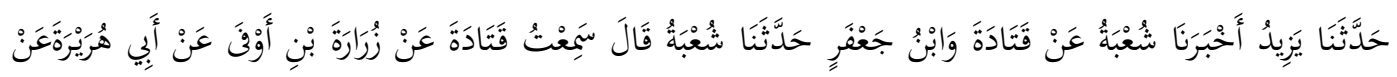

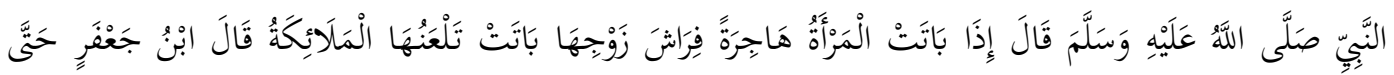
تَرِْجعَ 20

\section{Hadis Halaman 439}

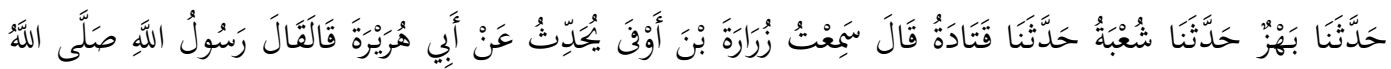

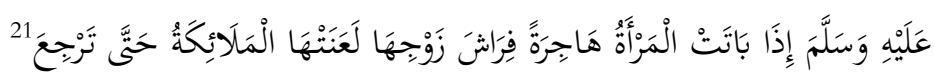

\section{Hadis halaman 468}

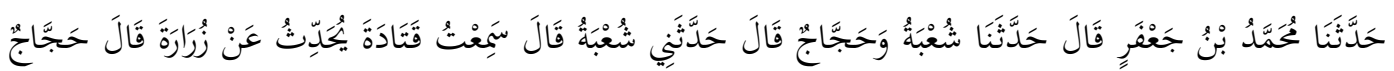

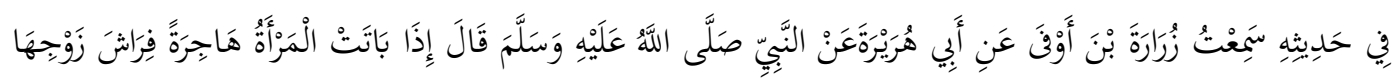
222

18 Ahmad bin Muhammad bin Hanbal. Musnad Ahmad bin Hanbal, (Beirut: Dar al-Fikr, T.th), juz II, Hlm. 255

${ }^{19}$ Ahmad bin Muhammad bin Hanbal., Hlm. 348

${ }^{20} \mathrm{Ahmad}$ bin Muhammad bin Hanbal., Hlm. 386

${ }^{21}$ Ahmad bin Muhammad bin Hanbal., Hlm. 439

${ }^{22}$ Ahmad bin Muhammad bin Hanbal., Hlm. 468 
FITRAH Jurnal Kajian Ilmu-ilmu Keislaman

Vol. 05 No. 1 Juni 2019

Hadis Halaman 480.

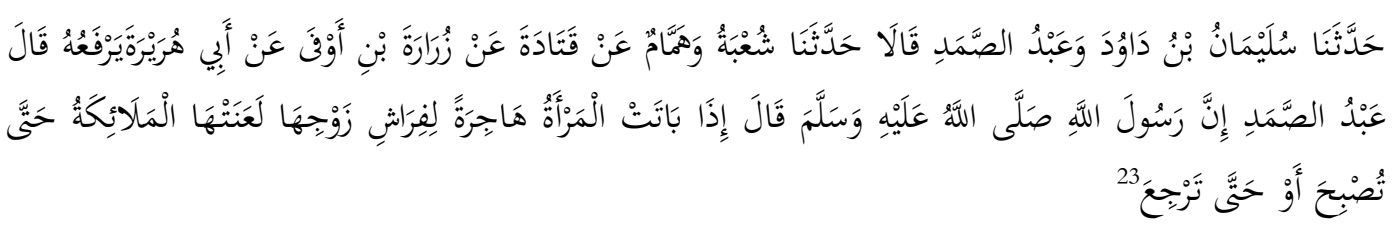

Hadis Halaman 519

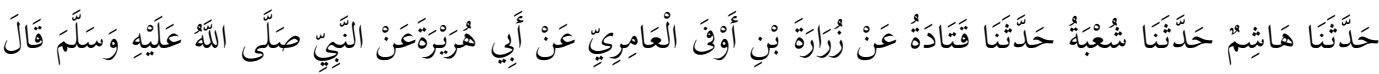

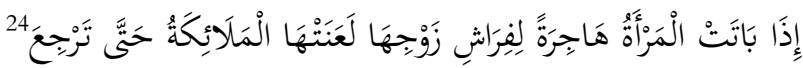

\section{Penilaian Kritikus Hadis}

Hadis tentang Dilaknatnya perempuan yang menolak panggilan suaminya, dilihat dari sanadnya dinilai sahih oleh Imam al-Bukhari dan Muslim, karena mereka berdua memasukkan hadis ini ke dalam kitab sahih mereka masingmasing, sebagaimana terlihat dalam kitab Mu'jam hadis di atas. Kemudian Imam at-Tirmizi menilainya dengan Hasan sahih gharib, ${ }^{25}$ Selanjutnya Muhammad Syakir dalam kitabnya Syarah Musnad Ibn Hanbal menilainya sahih. ${ }^{26}$

\section{Tema Pembahasan Hadis.}

Tema pokok yang terkandung dalam hadis ini adalah tentang masalah Dilaknatnya perempuan yang menolak panggilan suaminya.Yang menjadi permasalahan adalah bagaimanakah maksud Suami mengajak/memanggil Istri ke tempat tidur, menolak atau enggan untuk memenuhinya ajakan suami, Suami dalam keadaan marah, Malaikat melaknat istri sampai subuh.Sebelummengkaji tentang makna kandungan hadis, terlebih dahulu di paparkan ayat-ayat Alquran yang berkaitan dengan esensi kandungan hadis di atas dalam rangka menyokong makna kandungan hadis dimaksud.

${ }^{23} \mathrm{Ahmad}$ bin Muhammad bin Hanbal., Hlm. 480.

${ }^{24}$ Ibid., Hlm. 519

${ }^{25}$ Imam Tirmizi memandang hadis hasan sahih bernilai lebih tinggi daripada hadis hasan, tapi rendah daripada hadis sahih.Sedangkan hadis sahih yang diberi sifat gharabah berpijak pada pertimbangan bahwa hadis sahih kadang-kadang diriwayatkan dari satu sumber sehingga hadis itu dianggap gharib.Mengenai istilah-istilah yang digunakan oleh Imam Tirmizi terdapat hal-hal yang tidak jelas karena dia sendiri tidak memberikan batasan-batasan terhadap istilah-istilah tersebut sehingga timbul perbedaan pendapat dalam memahaminya. NawirYuslem. Kitab Induk Hadis Sembilan, (Jakarta: Hijri Pustaka Utama, 2011), Hlm. 103.

${ }^{26}$ Ahmad MuhammadSyakir.Syarah Musnad Ahmad bin Hanbal, diterjemahkan oleh Aziz Noor dan Ulin Nuha, (Jakarta: Pustaka Azzam, 2010), juz. VIII, Hlm. 343. 
4. Ayat-ayat yang Berkaitan dengan Masalah Dilaknatnya perempuan yang menolak panggilan suaminya.

a. Surat ar-Rum ayat 21 yang menjelaskan tentang istri adalah pasangan suami, agar saling mendapatkan ketenangan.

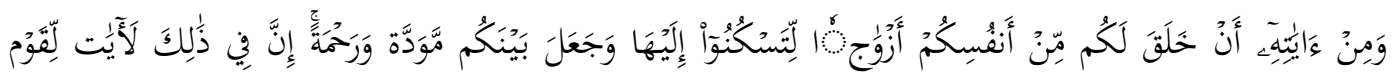

Artinya: Dan di antara tanda-tanda kekuasaan-Nya ialah Dia menciptakan untukmu isteri-isteri dari jenismu sendiri, supaya kamu cenderung dan merasa tenteram kepadanya, dan dijadikan-Nya diantaramu rasa kasih dan sayang. Sesungguhnya pada yang demikian itu benar-benar terdapat tanda-tanda bagi kaum yang berfikir.

b. Surat Al-Baqarah ayat 223 yang menjelaskan bahwa istri adalah tempat bercocok tanam (bersetubuh/berjimak) bagi seorang suami.

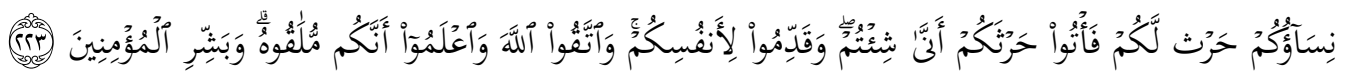

Artinya: Isteri-isterimu adalah (seperti) tanah tempat kamu bercocok tanam, Maka datangilah tanah tempat bercocok-tanammu itu bagaimana saja kamu kehendaki. dan kerjakanlah (amal yang baik) untuk dirimu, dan bertakwalah kepada Allah dan ketahuilah bahwa kamu kelak akan menemui-Nya. dan berilah kabar gembira orang-orang yang beriman.

Surat ar-R-m ayat 21 di atas menjelaskan tentang bahwa manusia hidup berpasang-pasangan, ada laki-laki ada perempuan. Laki-laki sebagai suami perempuan sebagai istri.Tujuan ini dari penciptaan ini agar hidup mereka mendapat ketenangan dan kasih sayang.Fitrah manusia menghendaki saling menemukan pasangan antara laki-laki dan perempuan.Surat Al-Baqarah ayat 223 di atas menjelaskan tentang istri adalah tempat meneruskan keturunan, yang didahului dengan hubungan suami istri yang disebut dengan istilah bercocok tanan (harsun).

Hubungan ayat ini dengan hadis yang dibahas adalah bahwa salah satu tujuan perkawinan menyalurkan nafsu syahwat pada tempat syah yaitu istri.Istri sebagai pasangan suami, sekaligus tempat bercocok tanam, untuk meneruskan keturunan, mendapatkan ketenangan dan kasih sayang, saling melengkapi antara keduanya. 
FITRAH Jurnal Kajian Ilmu-ilmu Keislaman

Vol. 05 No. 1 Juni 2019

5. Makna kandungan Hadis

a. Mengajak ke tempat tidur

Dalam konteks ini dari beberapa riwayat yang ada ditemukan dua

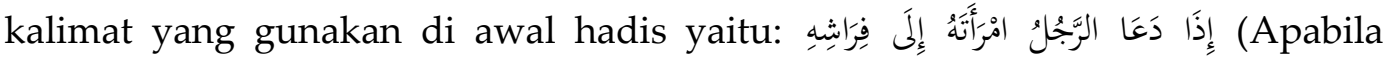

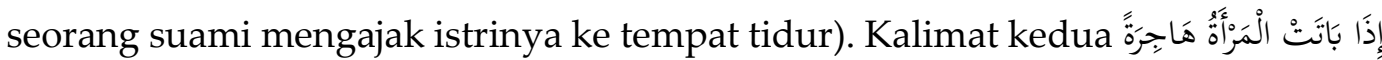

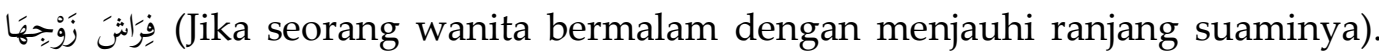
Walaupun kedua kalimat ini berbeda redaksinya, tetapi mengandung makna yang sama yaitu tidak memenuhi ajakan suami tempat pembaringan (jima'). Kata $d a^{\prime} a$, berasal dari kata da'a-yad'u-da'watan, secara bahasa bermakna menyeru, memanggil, mengajak, dan menjamu. ${ }^{27}$ Dalam konteks hadis ini adalah mengajak atau memanggil istri ke tempat tidur. Dalam kitab Fat al-Bari mengutip pendapat Ibn Abu Jumrah, makna zahir hadis adalah firasy (tempat tidur), tetapi maksudnya adalah kiasan terhadap perbuatan "jima"'.28 Hal ini di dukung oleh sabda Nabi dalam riwayat al-Bukhari dengan redaksi matannya:

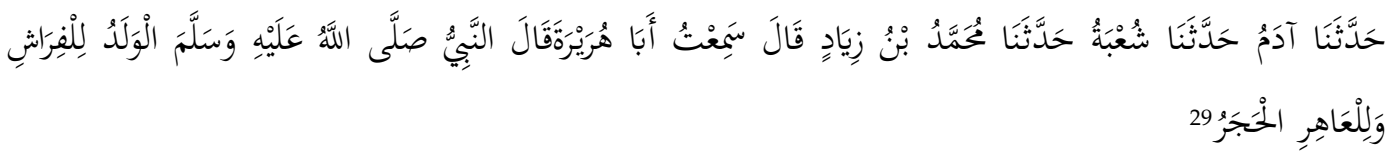

Artinya: Telah menceritakan kepada kami Adam telah menceritakan kepada kami Syu'bah telah menceritakan kepada kami Mu¥ammad bin Ziyad, dia berkata; aku mendengar Abu Hurairah menuturkan; Nabi shallallahu 'alaihi wasallam bersabda: "anak bagi pemilik kasur (pembaringan), dan bagi pezina adalah batu" .

Arti pemilik kasur (pembaringan) adalah suami yang mencampuri istrinya.Karena perbuatan mencampuri di lakukan di atas firasy (pembaringan). Penggunaan kata-kata yang bersifat tabu untuk disebut sangat banyak dalam Alquran dan al-Hadis. Salah satu seperti ayat di atas tentang istri tempat bercocok tanam (harsun) pada surat al-Baqarah 223 di atas.

${ }^{27}$ Mahmud Yunus. Kamus Arab Indonesia, (Jakarta: Mahmud Yunus waDzurariyah, 2010), Hlm.127.

${ }^{28}$ Ibn Hajar al-'Asqalani. Fathul Bari, diterjemahkan Amiruddin,(Jakarta: Pustaka Azzam, 2012), juz. XXV, Hlm.658. Pendapat ini sama dengan pendapat Abi Hamzah dalam kitab Abi alTayib Muhammad Syams al-Haqq al-'Azim 'Abadi. 'Aun al-Ma'bud Syarh Sunan Abi Dawud (Beirut: Dar al-Kutub al-'Ilmiyah, 1990), Juz, 5-6, Hlm. 126.

${ }^{29}$ Imam al-Bukhari, Op.cit., Juz. IV, Hlm. 461. 
Kewajiban untuk memenuhi panggilan suami sangat urgen, seperti tatkala istri sedang sibuk memasak di dapurpun, jika diajak suaminya harus memenuhi ajakan tersebut sebagaimana hadis di bawah ini:

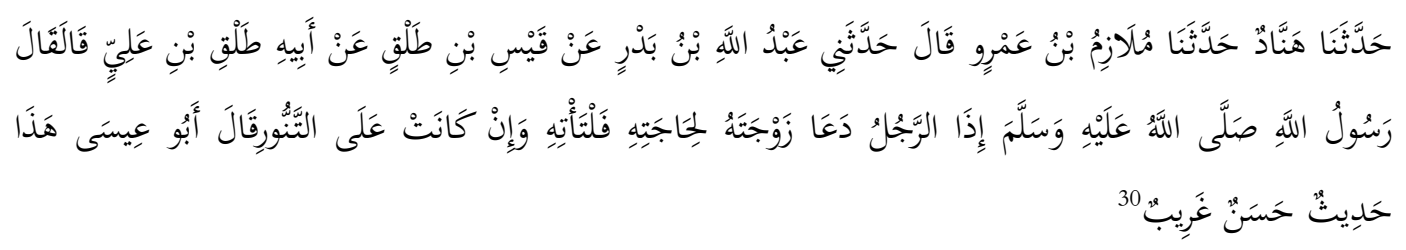

Artinya: Telah menceritakan kepada kami Hannad, telah menceritakan kepada kami Mulazim bin 'Amr berkata; Telah menceritakan kepadaku Abdullah bin Badar dari Qais bin halq dari Bapaknya, halq bin 'Ali berkata; Rasulullahshallallahu 'alaihi wasallam bersabda: "Jika seorang suami mengajak istrinya untuk memenuhi hasratnya, maka hendaknya dia mendatanginya, walau dia sedang sibuk berada di dapur." Abi Isa berkata; " Abu Isa berkata; "Ini adalah hadits hasan gharib."

Menurut Yusuf Qardawi dari hadis ini dipahami bahwa masalah jima' secara fitrah dan kebiasaan laki-laki sifatnya agresif, sedangkan wanita sifatnya pasif. Laki-laki lebih keras kemauannya dan lebih sedikit kesabarannya dibanding wanita.Berbeda dengan opini sebagian manusia bahwa syahwat wanita lebih besar daripada laki-laki.Hal ini dibuktikan bahwa kenyataan yang diterangkan oleh syara', hadis di atas. ${ }^{31}$

b. Enggan atau tidak mau datang memenuhi ajakan suami

Maksud kata فَلَمْ تَأْنِهِ فَبَاتَ غَضْبَانَ عَلَيْهَها (maka ia tidak atau enggan datang membuat suaminya marah). Dalam Syarah 'Aunal-Ma'bud maksudnya adalah haram hukumnya bagi istri menolak persenggamaan (jima') dengan suami. ${ }^{32}$ Kewajiban untuk memenuhi hasrat suami untuk berjima' gugur apabila sang istri dalam keadaan uzur syar'i seperti puasa fardhu, dan keadaan ihram. Tetapi

${ }^{30}$ Imam at-Tirmizi, Op.cit, Juz. III, Hlm. 431

${ }^{31}$ Yusuf Qardawi, Fatwa-Fatwa Kontemporer, diterjemahkan oleh As'ad Yasin, (Jakarta: Gema Insani Press, 1996), 610.

${ }^{32}$ Abi al-Tayyib Muhammad Syams al-Haq al-'Azim Abadi, Aunal-Ma'bd Syarh Sunan Abi Dawud, Juz. V-VI, Hlm. 126. 
FITRAH Jurnal Kajian Ilmu-ilmu Keislaman

Vol. 05 No. 1 Juni 2019

walaupun dalam keadaan haid, suami memiliki hak untuk bersenang-senang (istimta') dengan tubuh istri, kecuali pada kemaluannya. ${ }^{33}$

Dalam kajian ini berkaitan dengan tujuan perkawinan, hak-hak suami, dan kewajiban-kewajiban istri.Diantara tujuan perkawinan merupakan hak suami adalah menyalurkan nafsu syahwat secara sah dan mendapatkan keturunan, yaitu dari istri yang telah dinikahi. ${ }^{34}$ Oleh karena itu, salah satu kewajiban istri menyahuti nafsu syahwat suami.Dengan melayani nafsu syahwat tersebut berarti istri telah membantu suami dan mencari keredhannya.Hal ini dilatarbelakangi bahwa kesabaran seorang suami meninggalkan jima' lebih lemah di banding kesabaran istri. ${ }^{35}$

Dalam konteks ini tujuan pernikahan dapat menundukan pandangan dan menjaga kemaluannya, sebagaimana dinyatakan hadis di bawah ini:

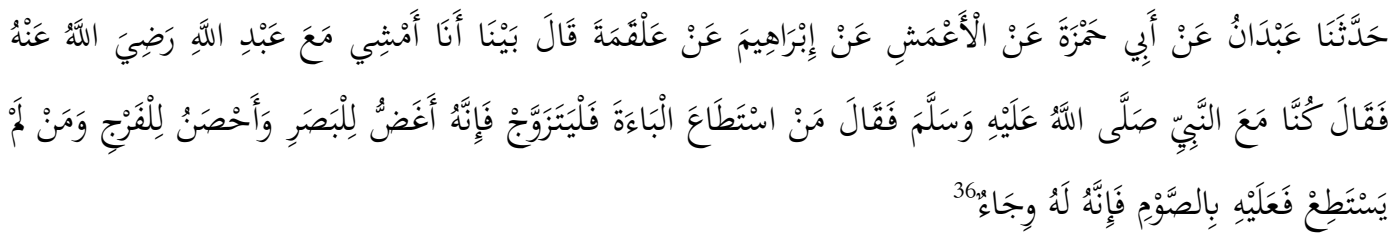

Dengan pernikahan, maka ada hak-hak suami pada istri dan ada kewajiban istri kepada suami, demikian juga sebaliknya.Hadis ini menunjukkan tentang pernikahan tersebut menyelamatkan kemaluan, oleh karenanya tidak ada hak istri untuk tidak memberikan hak-hak suaminya. Sebaliknya jika hakhak suami tersebut tidak diberikan oleh istri akan mengakibatkan gejolak syahwat suami melakukan hal-hal yang menyimpang dalam seksual, seperti mengkhayal yang bukan-bukan, atau menimal akan menimbulkan kegoncangan ketegangan dalam jiwa dan syahwat. ${ }^{37}$

Menyahuti ajakan suami jima' inilah maka syara' mengharamkan istri puasa sunnat ketika suami di rumahnya, kecuali istri terlebih dahulu meminta izin. Sebab hak suami lebih utama untuk dipenuhi daripada pahala sunnah. Hal ini diperkuat oleh hadis Nabi

\footnotetext{
${ }^{33}$ Imam an-Nawawi. Syarah Sahih Muslim, diterjemahkan oleh Wawan Junaidi, (Jakarta: Pustaka Azzam, 2010), Juz. X, Hlm. 16.

${ }^{34}$ Yusuf Qardawi. Halal dan Haram, diterjemahkan oleh Mu'ammalHumaidi, (Bina ilmu: Surabaya, 2000), Hlm. 267.

${ }^{35}$ Ibn Hajar al-'Asqalani.Fathul Bari, juz. XXV, Hlm.662

${ }^{36}$ Imam Bukhari, Op.cit., Juz. II, Hlm. 352.

${ }^{37}$ Yusuf Qardawi, Fatwa-Fatwa Kontemporer, diterjemahkan oleh As'ad Yasin, (Jakarta: Gema Insani Press, 1996), Hlm.611.
} 


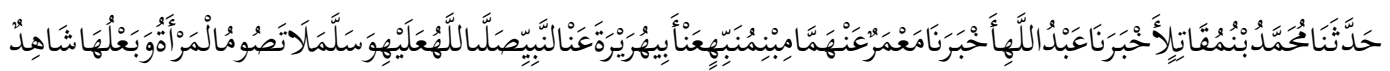

Artinya: Telah menceritakan kepada kami Muhammad bin Muqatil Telah mengabarkan kepada kami Abdullah Telah mengabarkan kepada kami Ma'mar dari Hammam bin Munabbih dari Abu Hurairah dari Nabi shallallahu 'alaihi wasallam, beliau bersabda: "Janganlah seorang wanita berpuasa padahal suaminya sedang ada, kecuali dengan seizinnya."38

Dalam hubungan suami istri ini, Islam juga memberikan kesimbangan atas hak istri kepada suami, yang mana suami juga harus memperhatikan hasrat dan syahwatnya istri. Hal ini dijelaskan Nabi sebagaimana hadis di bawah ini:

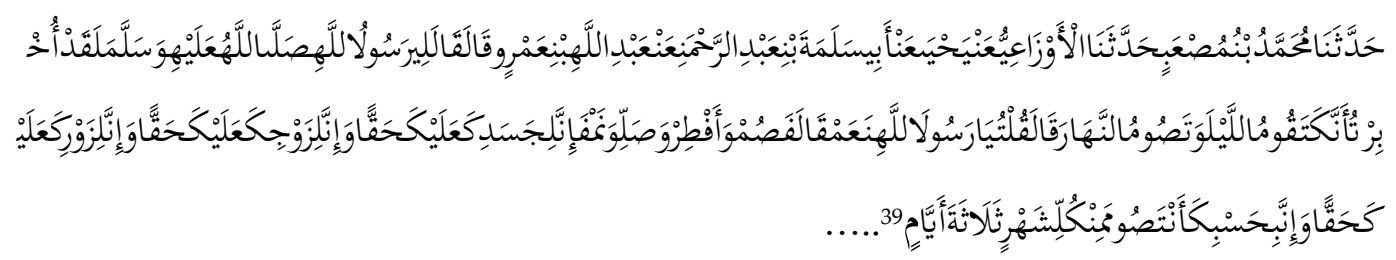

Artinya: Telah menceritakan kepada kami Muhammad bin Mush'ab berkata; telah menceritakan kepada kami Al Auza'i dari Yahya dari Abu Salamah bin Abdurrahman dari Abdullah bin 'Amru berkata: RasulullahShallallahu 'alaihi wa Salam bersabda kepadaku: "Aku telah mendapatkan kabar bahwa engkau shalat di malam hari dan puasa di siang harinya." Dia berkata; aku berkata; "Benar wahai Rasulullah." Beliau bersabda: "Hendaklah kamu berpuasa dan berbuka, shalat dan tidur, karena sesungguhnya badanmu mempunyai hak atas kamu, istrimu mempunyai hak atas kamu, dan sesungguhnya cukup bagimu itu jika engkau puasa tiga hari dalam satu bulannya." .....

Dalam hadis di atas di katakana bahwa istri punya hak pada suami, dalam artian suami harus memberikan nafkah bathin kepada istri dalam bentuk memberikan kepuasan nafsu seksual istri.Oleh karena itu, sebaiknya suami juga senantiasa selalu siap untuk memberikan kepuasan kepada istri.Hal ini berkaitan dengan hal-hal kewajiban memelihara rumah tangga.

Menurut Imam al-Ghazali seyogianya seorang suami mencampuri istrinya setiap empat malam sekali, dan itulah yang lebih adil, karena jumlah istri itu empat orang jumlah maksimal bagi yang berpoligami.Maka bolehlah suami mencampuri istrinya dengan jarak yang demikian.Namun boleh juga menambah

${ }^{38}$ Imam AL-Bukhari, Op.cit., Juz. II. Hlm. 34.

${ }^{39}$ Imam Ahmad bin Hanbal. Op.cit., Juz. III, Hlm. 236. 
FITRAH Jurnal Kajian Ilmu-ilmu Keislaman

Vol. 05 No. 1 Juni 2019

atau mengurangi sesuai dengan kebutuhannya demi memeliharanya, karena memelihara itu kewajibannya. ${ }^{40}$

Dalam hubungan intim juga Islam memberikan aturan adabnya yang mana suami tidak boleh untuk menyenangkan hasratnya sendiri saja tanpa menghiraukan perasaan dan keinginan istri.Islam menganjurkan sebelum melakukan hubungan intim, terlebih dahulu harus mengadakan pemanasan agar memunculkan hasrat, seperti bercumbu, berpelukan, berciuman, atau semacamnya. Hal ini dijelaskan oleh Hadis Nabi :

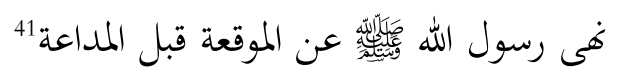

Artinya: Rasulullah SAW melarang melakukan hubungan Jima' (hubungan badan) sebelum bercumbu.

Imam al-Ghazali mengatakan jika suami hendak menyelesaikan hajatnya, hendaklah ia menunggu istri (jangan mencabut kemaluannya), sehingga istri merasa puas. Karena ketika syahwat sedang bergelora tetapi suami telah selesai, maka dapat menyakiti istrinya,karena kadang kala keluarnya manitidak sama dengan gelora syahwat istri. Tetapi apabila keluarnya mani dan ovum bersamaan itu merupakan kenikmatan bersama. Oleh karena itu suami tidak boleh memperhatikan diri sendiri dengan mengabaikan hasrat istri, karena dia merasa malu untuk aktif. ${ }^{42}$

c. Suami menjadi atau dalam keadaan marah

Maksud kata فَأَتْتْ فَبَاتَ غَضْبَانَ عَلَيْهَا (Maka istri menolaknya sehingga dia melalui malam itu dalam keadaan marah pada istrinya). Menurut Al-A'masy, dari sini diketahui alasan terjadinya laknat, karena pada saat seperti ini jelas bahwa dia telah melakukan kemaksiyatan, karena tidak melaksanakan kewajiban dan memberikan hak suaminya. ${ }^{43}$ Berbeda jika suaminya tidak marah atas perbuatan itu, maka mungkin suaminya telah memaafkannya atau juga meninggalkan haknya.Mengenai perkataannya dalam riwayat Zurarah,

\footnotetext{
40 Yusuf Qardawi. Fatwa-Fatwa Kontemporer, diterjemahkan As'ad Yasin, (Jakarta: Gema Insani Press, 1996, Hlm.613

${ }^{41} \mathrm{Ibn}$ Qayyim al-Jauziyah. Zadul Ma'ad, (Tp. Sunnah Muhammadiyah, T.Th), Juz. III, Hlm.309.

42 Yusuf Qardawi. Op.cit, Hlm. 614

${ }^{43}$ Ibn Hajar al-'Asqalani, Fathul Bari, juz. XXV, Hlm.660
} 


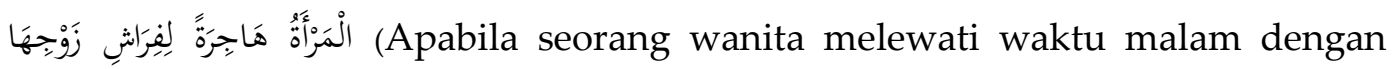
meninggalkan tempat tidur suaminya), Maka ini tidak di pahami secara zahir, yaitu istri yang meninggalkan. Terkadang maksud kata yang mengacu pada pola mufa'alah (makna timbal balik) adalah perbuatan itu sendiri, karena tidak tepat celaan dialamatkan kepada istri jika suami yang memulai meninggalkan, lalu suami memarahinya karena hal itu, atau suaminya meninggalkan, sementara istri dalam keadaan zalim dan belum menyadari dosanya, sehingga iapun meninggalkannya. Adapun jika suami yang memulai meninggalkan istrinya dalam keadaan zalim terhadap istrinya maka tidak berlaku ancaman. ${ }^{4}$

\section{d. Malaikat melaknat}

Maksud Malaikat melaknat pada hadis ini adalah Malaikat mendoakan yang tidak baik buat istri.Laknat berkaitan dengan rasa marah suami.Selagi suami masih merasa marah, maka laknat Malaikat terus berlanjut kepada istri.Jadi marah menjadi muncul laknat kepada istri.Laknat tidak berlaku jika suami tidak marah walaupun istri tidak memenuhi permintaan suami.Ia ikhlas atas ketidak hadiran istrinya disisi pembaringannya. ${ }^{45}$

$\mathrm{A}^{-}$- $^{\circ}$ abrani mengutip hadis Ibn ‘Umar dan di Nisbatkan kepada Nabi saw:

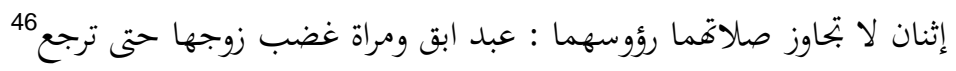

(Dua golongan yang shalat keduanya tidak melewati kepala mereka, yaitu: Hamba yang melarikan diri, wanita yang suaminya marah hingga ia kembali). Hadis ini shahih menurut al-Hakim. Menurut Al-Muhallab, hadis ini menunjukkan bahwa menghalangi hak-hak pada badan atau harta, termasuk perkara yang mendatangkan kemarahan Allah, kecuali Dia melimpahkan ampunan-Nya. Di dalamnya terdapat pembolehan laknat bagi orang yang maksiyat dan muslim dengan maksud menakut-nakutinya agar tidak terjerumus dalam perbuatan itu. Apabila ia terjerumus, maka didoakan agar cepat tobat dan mendapat hidayah.

Menurut Ibn Hajar pembatasan ini tidak disimpulkan dari hadis secara langsung bahkan di ambil dari dalil-dalil lain. Sebagian syeikh kami sepakat dengan apa yang dikatakan Al-Muhallab yang berdalil dengan hadis di atas untuk membolehkan melaknat pelaku maksiyat, namun tentu saja pernyataan ini

${ }^{44} \mathrm{Ibn}$ Hajar al-'Asqalani, Fathul Bari, juz. XXV, Hlm.660

${ }^{45}$ Imam an-Nawawi.Syarah Sahih Muslim, Juz. X, Hlm. 16.

${ }^{46}$ Hadis ini di kutip Ibn Hajar al-'Asqalani. Fathul Bari, juz. XXV, Hlm.661 
FITRAH Jurnal Kajian Ilmu-ilmu Keislaman

Vol. 05 No. 1 Juni 2019

perlu ditinjau kembali. Pendapat yang lebih benar, maksud mereka yang melarang melaknat adalah maknanya secara bahasa, yakni menjauhkan dari rahmat Allah, dan ini tidak patut di doakan untuk seorang muslim, bahkan seharusnya di mintakan hidayah, taubat, dan kembali dari perbuatan maksiyat. Adapun yang diperbolehkannya adalah mencelanya.Hal ini berdasarkan makna Urf. Hadis di bab ini menyinggung Malaikat yang melakukan laknat. Namun yang demikian tidak berkosekuensi perbuatan tersebut di perbolehkan secara mutlak.

Menurut al-Muhallab pada hadis ini dikatakan bahwa Malaikat mendoakan kecelakaan bagi pelaku maksiyat selama mereka berada dalam kemaksiyatannya.Ini menunjukkan mereka juga mendoakan kebaikan bagi pelaku ketaatan selama mereka dalam ketaatan.Ibn Abu Jamrah berkata, "Apakah Malaikat yang melaknat adalah para pemelihara atau selain mereka ?.Ada dua kemungkinan.“Saya berkata, kemungkinan ada sebagian Malaikat yang ditugaskan khusus untuk itu. Kemungkinan ini diindikasikan pernyataan umum dalam riwayat Muslim, yaitu:

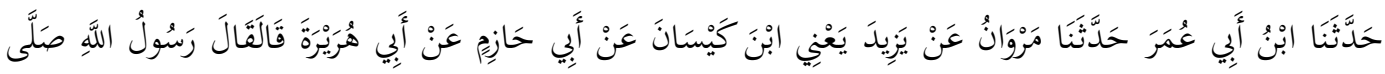

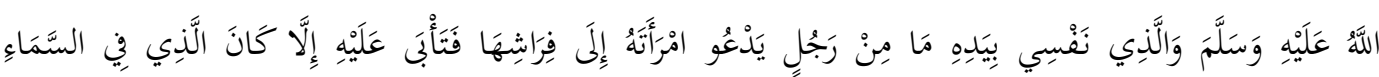

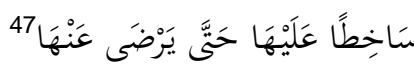

Artinya: Telah menceritakan kepada kami Ibnu Abi Umar telah menceritakan kepada kami Marwan dari Yazid yaitu Ibnu Kaisan dari Abu Hazim dari Abu Hurairah dia berkata; Rasulullahshallallahu 'alaihi wasallam bersabda: "Demi dzat yang jiwaku berada di Tangan-Nya, tidaklah seorang suami mengajak istrinya ke ranjang (untuk bersenggama) sedangkan dia enggan, melainkan yang ada di langit murka kepadanya sampai suaminya mema'afkannya".

Kalimat "yang berada di langit", jika yang dimaksud adalah penghuninya adalah Malaikat. Dia menambahkan pula: “disini terdapat dalil tentang diterimanya doa Malaikat, baik berupa kebaikan atau keburukan, karena Nabi saw menakuti dengan hal itu.

Sebagai penutup penjelasannya, Abu Jamrah mengatakan, “Di sini terdapat isyarat untuk konsisten dalam ketaatan kepada Allah dan bersabar dalam beribadah kepada-Nya, sebagai balasan atas pengawasan-Nya terhadap

\footnotetext{
${ }^{47}$ Imam Muslim, Juz. II., Hlm. 231.
} 
hamba-hamba-Nya yang tidak meninggalkan sesuatu daripada hak-hak-Nya melainkan dijadikan untuknya siapa yang menegakkannya, hingga dijadikan Malaikat melaknat siapa yang membuat marah seseorang dan mencegah syahwatnya. Bagi seorang hamba hendaknya memenuhi hak-hak Rabbnya yang diminta-Nya.Jika tidak, maka alangkah buruknya sikap pengabaian dari yang fakir dan butuh kepada yang kaya dan banyak kebaikan". ${ }^{48}$

e. Sampai Tarji', Redha, dan Subuh

Dari hadis-hadis yang berkaitan dengan permasalahan ini, ada tiga kata yang di gunakan lamanya laknat tersebut berlangsung, yaitu:

Pertama, kata حَتََّّ تَرْهِع (hingga ia kembali ke pembaringan suaminya), Ini bermakna bahwa tidak datangnya istri ke pembaringan (firas) tatkala menyengaja atau ia belum menyadari bahwa ia telah berbuat salah (dosa) karena tidak memenuhi hak suami terhadap dirinya. Tetapi tatkala ia telah menyadari, ia datang ke pembaringan suami untuk memenuhi kewajibannya maka laknat berakhir. Secara tersirat kembalinya istri ke pembaringan suami menghilangkan rasa marah suami.

Kedua kata حَتَّى يَضْضَى عَنْها, (hingga iaredha kepada istrinya). Kata ini menunjukkan beberapa makna: Pertama, bahwa secara spesifik laknat hilang jika suami telah redha dan hilang rasa marah dengan kedatangan istri ke pembaringannya. Kedua, Kedatangan istri ke tempat pembaringan, tetapi marahnya suami belum hilang, menandai belum redhanya suami, sehingga laknat terus berlanjut.Dalam konteks ini laknat hilang sampai rasa marah suami hilang.Ketiga, Walaupun istri tidak datang ke pembaringan suami, laknat tidak berlaku karena suami redha atas hal tersebut dikarenakan sesuatu hal, yang intinya suami tidak marah dengan ketidak hadiran istri di sisi pembaringannya.

Ketiga, حَتََّّ تُصنبحَ (hingga waktu subuh), Laknat terus berlanjut kepada istri, sampai waktu subuh. Walaupun istri telah datang ke pembaringan suami, tetapi suami belum redha dan masih marah kepada istri, maka batas akhir laknat tersebut hanya sampai waktu subuh (terbit fajar).Jika waktu subuh telah sampai maka laknat tersebut hilang kepada istri walaupun suami masih merasa marah kepadanya.Jadi masa berlaku laknat memiliki batas sampai di waktu subuh

${ }^{48}$ Ibn Hajar al-'Asqalani.Fathul Bari, juz. XXV, Hlm.662 
FITRAH Jurnal Kajian Ilmu-ilmu Keislaman

Vol. 05 No. 1 Juni 2019

(waktu fajar) dan hilangnya keinginan suami terhadapnya. ${ }^{49}$ Kenapa di katakan waktu subuh ?, Karena menurut Abu Jamrah: Seakan-akan rahasianya adalah karena secara keumuman dan penekanannya maknanya melaksanakan jima' di malam hari, yaitu yang dimulai dari masuknya waktu Maghrib dan datangnya waktu Subuh, tetapi bukan berarti jika di siang hari suami mengajak istri untuk jima', lalu istri boleh untuk menolaknya. ${ }^{50} \mathrm{Hal}$ ini kuatkan dengan hadis Nabi :

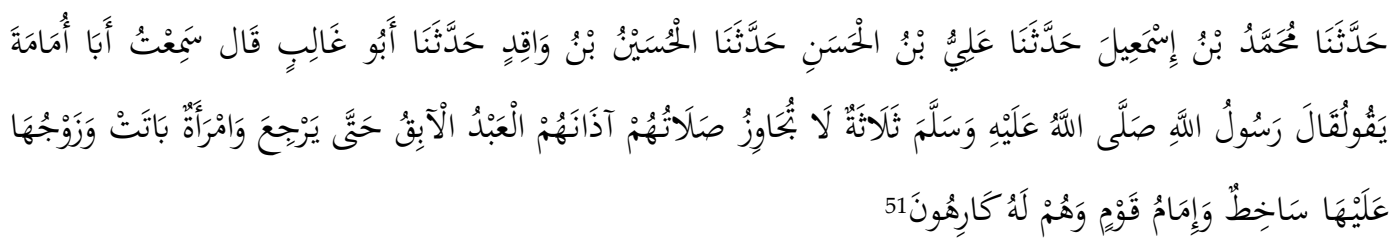

Artinya: Telah menceritakan kepada kami Muhammad bin Isma'il berkata; telah menceritakan kepada kami Ali bin Al Hasan berkata; telah menceritakan kepada kami Al Husain bin Al Waqid berkata; telah menceritakan kepada kami Abu Ghalib ia berkata; "Aku mendengar AbuUmamah berkata; "Rasulullahshallallahu 'alaihi wasallam bersabda: "Tiga orang yang shalatnya tidak akan melampaui telinga mereka; seorang budak yang kabur hingga ia kembali, seorang istri yang bermalam sementara suaminya dalam keadaan marah dan seorang imam bagi suatu kaum sedangkan mereka tidak suka".

Pernyataan-pernyataan ini disebutkan secara mutlak mencakup malam dan siang, tidak ada pengkhususan pada satu sisi saja, seperti malam atau siang saja.Istri harus siap sedia melayani suami kapan saja dia kehendaki, kecuali hanya di waktu adanya uzur syar'i.Wallahu'alam.

\section{PENUTUP}

1. Hadis tentang Dilaknatnya perempuan yang menolak panggilan suaminya, dilihat dari sanadnya dinilai sahih oleh Imam Bukhari dan Muslim, karena mereka berdua memasukkan hadis ini ke dalam kitab sahih mereka masing-masing. Kemudian Imam Tirmizi menilainya dengan hasan sshih gharib. Selanjutnya

\footnotetext{
${ }^{49}$ Imam an-Nawawi.Syarah Sahih Muslim, Juz. X, Hlm. 16.

${ }^{50} \mathrm{Ibn}$ iajar al-'Asqal \pm ni.Fat $¥ u l B^{2} r^{3}$, juz. XXV, Hlm.662 Pendapat yang sama juga dikemukakan oleh Syih \pm b al-D ${ }^{3} n A^{3}$ al- ${ }^{\prime} A b b \pm s A ¥ m a d$ bin Mu¥ammad as-Sy $\pm f^{\prime}{ }^{3}$ al-Qas ${ }^{-} a l \pm n^{3}$. Irsy $\pm d$ as-S $\pm r^{3}$, (Beirt: D \pm r al-Kitab al-Ilm³ yah, 1992), juz. VII, Hlm.159.

${ }^{51}$ Imam at-Tirmizi.Sunan at-Tirmizi, Bab Ma ja'afiman um qaumwa hum lahukarihun. Nomor hadis. 328.
} 
Muhammad Syakir dalam kitabnya Syarah Musnad Ibn Hanbal menilainya sahih.

2. Makna suami mengajak istri ke tempat tidur (firasy) merupakan makna kiasan. Makna yang sesungguhnya adalah mengajak untuk melakukan jima'. Karena tempat melakukan jima' adalah di atas tempat tidur (firasy). Oleh karena itu wajib hukumnya istri untuk memenuhi ajakan suami untuk melakukan hubungan jima'.

3. Makna Istri menolak ajakan suami adalah tidak dipenuhi ajakan suami untuk melakukan jima' tanpa ada uzur syar'i, seperti puasa fardu dan ihram. Haram hukumnya istri menolak ajakan suami untuk melakukan jima'. Walaupun dalam keadaan haid, jika suami mengajak bersenang-senang (istimta'), istri harus memenuhi, karena ada kebolehan suami untuk bersenang-senang terhadap istri, kecuali pada kemaluannya. Begitu pentingnya menyahuti ajakan suami jima' ini, maka syara' mengharamkan istri puasa sunnat ketika suami di rumahnya, kecuali istri terlebih dahulu meminta izin. Sebab hak suami lebih utama untuk dipenuhi daripada pahala sunnah (puasa sunnah).

4. Maksud suami marah kepada istri karena tidak melaksanakan kewajiban dan memberikan hak suaminya. Salah satu hak suami ada pada badan istri yaitu menyalurkan syahwat dan bersenang-senang, Jika hak-hak suami ini tidak dipenuhi oleh istri, maka mendatangkan kemarahan Allah, kecuali Dia melimpahkan ampunan-Nya. Berbeda jika suaminya tidak marah atas perbuatan itu, atau ia telah memaafkannya atau juga meninggalkan haknya. Dari marah suami inilah pangkal munculnya laknat kepada istri.

5. Maksud Malaikat melaknat pada hadis ini ada dua pendapat, Pertama: Malaikat mendoakan yang tidak baik buat istri, seperti mendapatkan kecelakaan selagi mereka berada dalam kemaksiyatan, karena tidak memberikan hak-hak suami. Tujuan laknat bagi orang yang maksiyat dengan maksud menakut-nakutinya agar tidak terjerumus dalam perbuatan itu. Apabila ia terjerumus, maka didoakan agar cepat tobat dan mendapat hidayah.Kedua: Menjauhkan istri dari rahmat Allah, atau tidak mendapat kasih sayang dari Allah swt.

6. Masa berlaku laknat dipahami tiga macam dari akhir periwayatan hadis yang ada. Pertama :Laknat kepada istri bisa sampai waktu istri kembali ke tempat tidur suami karena telah menyadari kesalahan dan bertaubat. Kedua: Laknat sampai suami redha dan memaafkan atas kesalahan istri. Ketiga: Laknat terus berlanjut hingga subuh walaupun rasa marah suami belum 
FITRAH Jurnal Kajian Ilmu-ilmu Keislaman

Vol. 05 No. 1 Juni 2019

berakhir. Masa laknat di tandai dengan hilang sifat marah pada diri suami dan datangnya waktu fajar.

7. Hikmah dibalik adanya kewajiban istri memenuhi ajakan suami untuk berjima', secara zahir ditunjukkan hadis untuk menghindari laknat dari Malaikat. Secara umum dalam rangka mengimplementasikan tujuan perkawinan, seperti tempat penyaluran nafsu syahwat yang sah dan bersenang-senang, dan tempat meneruskan keturunan. Secara khusus untuk menghindari gejolak syahwat suami untuk melakukan hal-hal yang menyimpang dalam seksual, seperti mengkhayal yang bukan-bukan, atau menimalakan menimbulkan kegoncangan ketegangan dalam jiwa dan syahwat. 


\section{DAFTAR PUSTAKA}

Al-Aini, Mahmud bin Ahmad Badr al-Din. Umdatul Qari, T.tp: Idarat athThiba'ah al-Muniriyah, 2012 juz. XII

'Abadi, Abi al-Tayib Muhammad Syams al-Haqq al-'Azim. 'Aun al-Ma'bud Syarh Sunan Abi Dawud, Beirut: Dar al-Kutub al-'Ilmiyah, 1990, Juz, 5-6

Adhim, Muhammad Fauzil, dkk. Menikah Memuliakan Sunnah, Yogyakarta: Darul Haq, 2013

An-Naisaburi, Abu Husin Muslim bin Hajjaj al-Qusayri, Sahih Muslim, Kairo: Maktabah al-Misriyah, T.th, Juz. II

Al-Asqalani, Ibn Hajar. Fathul Bari, diterjemahkan Amiruddin, Jakarta: Pustaka Azzam, 2012, juz. XXV

Baidan, Nasiruddin. Metodologi Penafsiran Al-quran, Yogyakarta: Pustaka Pelajar, 1997

Al-Bukhari, Abu Abdillah Muhammad bin Ismail. Sahih al-Bukhari, Beirut: Dar alMutabi' Sya'bi, T.th, Juz. III

Ad-Darimi, Imam, Sunan ad-Darimi, Libanon; Dar al-Fikr, 1998, juz. II

Fillah, Salim A.. Nikmatnya Pacaran Setelah Menikah, Yogyakarta: Pro-U Media, 2008

Hanbal, Ahmad bin Muhammad bin. Musnad Ahmad bin Hanbal, Beirut: Dar alFikr, T.th, juz II

Al-Jauziyah, Ibn Qayyim. Zadul Ma'ad, Tp. Sunnah Muhammadiyah, T.Th, Juz. III

Munawwir, Warson. Kamus al-Munawir, Jakarta: Pustaka progresif, 1997

Munir, Samsur. Ilmu Dakwah, Jakarta: Amzah, 2009

Manzur, Ibn. Lisan al-Arab, Madinah: Dar al-Hadis, 2002

An-Nawawi, Imam. Syarah Sahih Muslim, diterjemahkan oleh Wawan Junaidi, Jakarta: Pustaka Azzam, 2010, Juz. X

Al-Qastalani, Syihab al-Din Abi al-'Abbas Ahmad bin Muhammad as-Syafi'i. Irsyad as-Sari, Beirut: Dar al-Kitab al-Ilmiyah, 1992, juz. VII 
FITRAH Jurnal Kajian Ilmu-ilmu Keislaman

Vol. 05 No. 1 Juni 2019

Qardawi, Yusuf. Fatwa-Fatwa Kontemporer, diterjemahkan oleh As'ad Yasin, Jakarta: Gema Insani Press, 1996

------. Halal dan Haram, diterjemahkan oleh Mu'ammal Humaidi, Bina ilmu: Surabaya, 2000

Simanjuntak, Julianto, https://www.kompasiana.com, 15 Nopember 2011 / diperbarui 15 Nopember 2011, diakses tanggal 5 April 2019.

Al-Sijistani, Abu Dawud Sulaiman al-Asy'ab. Sunan Abu Dawud, Beirut: Dar alFikr. T.th, Juz. III

Syakir, Ahmad Muhammad. Syarah Musnad Ahmad bin Hanbal, diterjemahkan oleh Aziz Noor dan Ulin Nuha, Jakarta: Pustaka Azzam, 2010, juz. VIII

At-Tahhan, Mahmud. Usul al-Takhrij wa Darah al-Asanid, Beirut: Dar al-Quran alKarim, 1979

Al-Usaimin, Muhammad bin Saleh. Durul wa fatawa al-Haram al-Madani, Beirut: Dar al-Fikr, 2007

Yuslem, Nawir. Kitab Induk Hadis Sembilan, Jakarta: Hijri Pustaka Utama, 2011

Yunus, Mahmud. Kamus Arab Indonesia, Jakarta: Mahmud Yunus waDzurariyah, 2010

Wensick, A.J. Al-Mu'jamal-Mufahras li ahadisin an-Nabawi, Leiden: E.J. Brill, 1942, juz.VI 